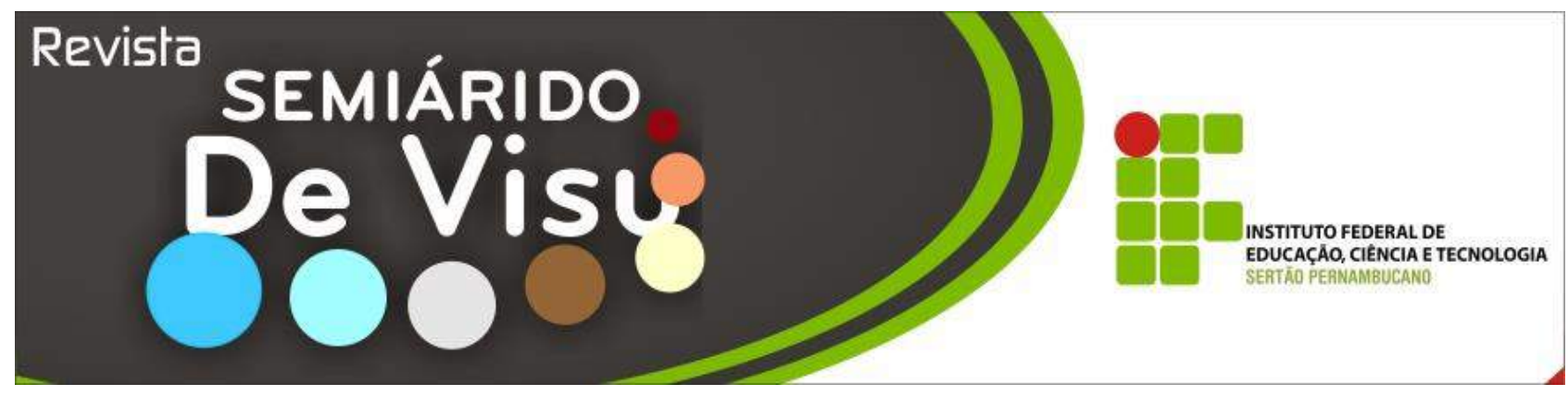

\title{
A escolha pela docência: decisão para a vida inteira
}

\author{
Maria do Socorro Tavares Cavalcante Vieira ${ }^{1}$ \\ ${ }^{1}$ BR 407, KM 08 - Jardim São Paulo. Petrolina/PE CEP 56314-520- 87 2101.4300. E-mail: socorro.tavares@ifsertao- \\ pe.edu.br
}

\begin{abstract}
RESUMO: Este trabalho é um recorte de um estudo maior, sobre vida docente, que considera as atividades laborais nos ambientes escolares como determinantes de comportamentos nos outros aspectos da vida cotidiana. A partir dos estudos sobre ciclos de vida profissional dos professores foi abordando o aspecto "entrada na carreira" as considerações aqui apresentadas objetivam descrever os motivos que influenciaram a escolha pela docência dos professores que atuam no ensino médio integrado do Campus Petrolina do IF Sertão PE. Foram considerados os estudos que descrevem a carreira docente e que tratam de explicar como acontece a decisão pelo magistério. Especificamente houve a pretensão de buscar nas histórias de vida dos professores, utilizando-se de dos princípios da pesquisa qualitativa com enfoque biográficonarrativo, fatores que contribuem para as escolhas concernentes ao ingresso e permanência na profissão. Por meio de entrevistas semiestruturadas, foram ouvidos professores que atuam na modalidade escolhida para o estudo enfatizando o aspecto "decisão pelo magistério". O estudo trouxe à baila os aspectos vacação e tradição familiar na profissão docente como elementos que influenciaram de forma contundente o acesso à carreira.
\end{abstract}

Palavras-chave: Profissionalização, Vocação, Tradição.

\section{The choice for teaching: decision for life}

\begin{abstract}
This paper is a cross-section of a larger study on teacher life, which considers work activities in school settings as determinants of behavior in other aspects of everyday life. From the studies on the professional life cycles of the teachers, the "career entry" aspect was taken into account. The considerations presented here are intended to describe the reasons that influenced the choice of the teachers who work in the integrated secondary education of the Campus Petrolina do IF Sertão PE. We considered the studies that describe the teaching career and that try to explain how the decision by the teaching profession happens. Specifically, there was the pretension to search in the life histories of the teachers, using the principles of qualitative research with biographical-narrative approach, factors that contribute to the choices concerning the entry and permanence in the profession. Through semi-structured interviews, teachers were heard who act in the modality chosen for the study emphasizing the aspect "decision by the teacher". The study brought to light the vacation and family tradition aspects of the teaching profession as elements that strongly influenced the access to the career
\end{abstract}

Keywords: Professionalization, Vocation, Tradition. 


\section{Introdução}

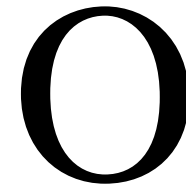
s sujeitos são, simultaneamente, seres genéricos e seres particulares, segundo Heller (1992), e suas histórias de vida se concretizam muitas vezes a partir das escolhas profissionais. A partir desse pressuposto entende-se que o entrelace entre profissionalização e vida cotidiana possibilita a formação de seres concretos, que vivem constantemente em construção e reconstrução de novos valores, perspectivas e projetos. Ao longo do estudo ficou claro que esse processo acontece pela reinterpretação de elementos oriundos de tradições diversas, articulados através de determinados valores que lhes conferem lógica e coerência.

A maneira como o docente constrói a sua imagem pessoal a partir de sua profissão muitas vezes interfere na definição de suas relações de trabalho e desenvolvimento de suas atividades pedagógicas e segundo Gatti (1996), as construções de identidade subsidiaram a maneira como o homem se coloca perante o mundo e diante das relações de trabalho. A imagem que o professor constrói de si mesmo e perante a sociedade faz parte do processo construtivo de sua identidade profissional.

Partindo desse pressuposto, buscou-se descrever os motivos que originaram trajetórias de vida docente de profissionais atuantes no ensino médio integrado do Campus Petrolina do Instituto Federal de Educação, Ciência e Tecnologia do Serão Pernambucano - IF Sertão PE. Todo o processo caracterizouse como uma pesquisa descritiva intencionando descrever fatos e fenômenos de determinada realidade, (TRIVIÑOS, 1987). Todavia, abordando história de vida e enfatizando o cunho narrativo, considerando que o valor da pesquisa descritiva se baseia na premissa de que os problemas podem ser estudados e as práticas repensadas por meio da observação objetiva e minuciosa dos fatos, segundo Gil (2008).

O modelo de profissional idealizado pela sociedade não condiz com a realidade da sociedade da informação e do conhecimento. Observa-se que a entrada na carreira gera uma tensão pela responsabilidade assumida e com as experiências vividas essas situações vão tomando outras nuances.

O suporte é o espaço em que, treinado (...) "aprende" a sobreviver ...) num tempo de dependência (...) que é necessário o ser humano para as mesmas coisas. Quanto mais cultural é o ser maior (...) sua dependência de cuidados speciais. (FREIRE, 2002, p.56, grifo do autor)

A profissão docente apresenta, desde os primórdios de sua história, características bem específicas independentes do contexto social, político, econômico e cultural em que está inserida. A educação formal advinda desses moldes por sua vez é emoldurada pelas ações que se desenrolam a partir desses parâmetros sociais. Um professor ao assumir suas funções em sala de aula começa a delinear sua nova identidade profissional perante o mundo que o cerca e não apenas o mundo do trabalho. Porém, essa nova identidade não negligencia a história de vida construída anteriormente.

As ideias de HUBERMAN, 1992 apud, ENCORE, 2004 configuraram-se como principais subsídios para delinear as bases do presente estudo. O autor classifica, sem engessar, a vida funcional docente em etapas que integram ciclos de vida, identificando assim percursos em momentos da carreira docente desde a entrada na carreira até as lamentações e o desinvestimento. Ressaltamos que sua proposta é válida para um grande número, ou até mesmo para a maioria, dos elementos de uma população estudada, mas nunca para a totalidade dessa população.

Segundo Holly (1992), o modo de pensar, sentir e atuar dos professores é influenciado pelo que eles são como pessoas, pelos diferentes contextos sociais onde crescem, aprendem e ensinam.

Porém, Dubar (1997) destaca o caráter dinâmico da identidade profissional, sempre em mutação em sua relação constante com questões como as taxas de desemprego, os níveis escolares, as origens sociais, as transformações tecnológicas, como também a transição entre conclusão dos estudos e a 
busca de uma atividade no mercado de trabalho. Ainda, segundo Dubar (1997, p. 114),

(...) o que constitui o processo de
construção (...) profissional não é só
uma identidade no trabalho, mas
também e sobretudo uma projeção
de si no futuro, a antecipação de uma
trajetória de emprego e o
desencadear de uma lógica de
aprendizagem ou melhor de
formação.

Nóvoa (1999) estabelece a relação entre profissionalização do professor, a construção de sua identidade e a sua história de vida. Mostra também que a racionalização do ensino impôs a separação entre o eu pessoal e o eu profissional do professor, estimulando sua crise de identidade, e localiza o início desse questionamento em meados da década de 80 , quando foi difundida a ideia que "o professor é a pessoa e uma parte importante da pessoa é o professor".

O presente estudo foi desenvolvido com professores que atuaram no ensino médio integrado do IF Sertão PE, Campus Petrolina e que estão enquadrados como professores de "Ensino Básico, Técnico e Tecnológico". Neste trabalho, a expressão "educação técnica" relaciona-se ao saber fazer, preparando o aluno para "exercer suas capacidades laborativa" (Laudares, Fiúza \& Rocha 2005, p.65) e ligada ao preparo para exercício em determina profissão.

A expressão "educação tecnológica" está ligada a uma concepção ampla e universal de formação, buscando o desenvolvimento integral do trabalhador, priorizando a formação de consciência crítica, o domínio de princípios científicos e tecnológicos, o desenvolvimento de habilidades sócio afetivas, cognitivas e éticas.

Profissionalidade é "a afirmação do que é específico na ação docente, isto é, o conjunto de comportamentos, conhecimentos, destrezas, atitudes e valores que constituem a

\footnotetext{
${ }^{1}$ Ensino Médio Integrado modalidade de ensino que possibilita a habilitação profissional técnica de nível médio ao mesmo tempo em que o estudante conclui a
}

especificidade de ser professor" (SACRISTÁN, 1999, p. 65).

A pesquisa inicial foi planejada para envolver professores nos quatro cursos de ensino médio em voga atualmente no Campus Petrolina: edificações, eletrotécnica, química e informática. De cada curso foram convidados, aleatoriamente, 06(seis) professores que aceitaram ser entrevistados sobre o que mais pesou em sua decisão pela docência como também permanência e consolidação.

\section{Material e Método}

A metodologia norteadora das atividades teve cunho qualitativo com esguelhas narrativas assim possibilitando a reconstrução de elementos de autobiografia dos professores pesquisados que fundamenta o objeto de pesquisa. Acreditase que o pesquisador ao visualizar histórias de vida de contexto narrativo considera que há compartilhamento de histórias de outros sujeitos na busca de uma identidade André (1997, p.72). Todavia caracterizou-se primordialmente como uma pesquisa descritiva.

O trabalho teve início com um Projeto de Iniciação Científica (PIBIC) que estudou os ciclos de vida docente convidando os professores do ensino médio integrado ${ }^{1}$ para que falassem das etapas de carreira evidenciando as etapas início da carreira, consolidação da carreira, balanço da carreira e preparo para aposentadoria. Para esse artigo recortou-se a primeira etapa, ou seja, o início da carreira com ênfase na escolha pela docência.

Para viabilizar o estudo, quando o projeto inicial estava em voga foi feita inicialmente uma pesquisa documental junto a Direção Geral de Pessoas na Reitoria do IF SERTÃO-PE sobre a contratação de professores para o Campus Petrolina no

última etapa da Educação Básica. Foi instituída pelo Decreto $\mathrm{n}^{\mathrm{o}} 5.154 / 04$. 
período de janeiro de 1993 a janeiro de 2013 . Nesse momento foram registradas áreas de formação desses professores.

A pesquisa documental assemelha-se
muito à pesquisa bibliográfica. A
principal diferença entre ambas está
na natureza das fontes. A fonte de
coleta de dados está restrita a
documentos, escritos ou não. Além
de ser realizada em bibliotecas a
pesquisa documental também pode
ser feita em (...) locais que sirvam
como fonte de informações para o
levantamento de documentos.
MOREIRA, 2006, p. 74)

Em seguida, foram selecionados e convidados formalmente os professores participantes, descrevendo o projeto e suas perspectivas de estudo. Após o aceite, foi constituída uma agenda de participação dos pesquisadores junto aos professores colaboradores para entrevistas. Na época da pesquisa ainda não estava implementado o Comitê de Ética na Pesquisa do IF Sertão PE, porém os participantes ficaram cientes que seus nomes e suas histórias não seriam revelados ou referenciados.

Numa próxima etapa foram feitas entrevistas semiestruturadas com os professores em estudo visando conhecer a história de vida e a opção pela carreira docente, com ênfase nos elementos que foram determinantes na decisão pela docência. Adotou-se uma questão norteadora das entrevistas: "quais os fatores foram determinantes na sua decisão pela carreira docente?". A pergunta objetivou ativar as memórias docentes no sentido de buscar em sua história de vida a melhor, mais completa ou mais significativa resposta

Para Ghedin (2008, p.143),

Conhecer envolve desvendar, na intimidade do real, a intimidade do próprio ser, que cresce justamente porque a ignorância se vai dissipando diante das perguntas e respostas construídas por si próprio, na qualidade de sujeito entregue ao conhecimento, o qual se mostra inerente à compreensão do próprio ser no mundo.

A fase de "entrada na carreira" consiste em o professor dar-se conta da distância entre o idealizado enquanto aluno do curso de formação, seja licenciatura, tecnólogo ou bacharelado e a concreta condição de trabalho. Porém durante as entrevistas os participantes também foram incentivados a falar sobre a fase de "estabilização" que indica um momento de maior estabilidade até mesmo de consolidação na carreira escolhida; a fase da "diversificação" quando o professor "se" autoriza a experimentar e a diversificar métodos de trabalho e de avaliação o que permite quebrar a rigidez de atuação do professor. E por fim puderam, caso desejassem "pôr-se em questão", ou seja, fazer um balanço da docência e seus condicionantes.

Os dados obtidos nas entrevistas foram compilados e os resultados registrados em formulários que permitiam separar as falas, e assim, possibilitar a visualização das respostas com clareza e compor respostas efetivas. Considerando a questão norteadora das entrevistas, um aspecto foi muito destacado, somando praticamente $96 \%$ das respostas foi a referência do termo: vocação.

\section{Resultados e discussões}

Os resultados das entrevistas que intencionavam responder à questão norteadora apontaram quase de forma unânime para um elemento que de certa forma se mistura à história da docência: a vocação. Não serão citadas nas discussões as falas ou opiniões dos docentes, será apresentado o aspecto apontado como elemento determinante da entrância na carreira docente e suas singularidades.

\section{Vocare, a vocação}

Considerando o número expressivo de professores que citou a "vocação" como motivo da escolha pela carreira docente cabe explicar o que pode ser considerado esse elemento, por vezes tão subjetivo, que abre espaços para muitas interpretações.

A vocação é um termo derivado do verbo no latim "vocare", que significa "chamar", é uma inclinação para exercer uma determinada profissão ou um talento (aptidão 
natural) para executar algo. $\mathrm{O}$ sentido original expressa um chamado espiritual para que as pessoas sigam uma religião ou uma missão divina destinada a alguns cristãos para exercerem o sacerdócio.

A vocação não partiu do ser humano nem porque ele decidiu ser chamado; sua escolha não foi uma preferência entre alternativas; em vez disso, o chamado de Deus foi inconfundível, ecoando como uma imperiosa intimação de Deus, de maneira que não lhe restou alternativa, senão obedecer (JOWETT, 1969, p. 11).

Acredita-se que falar em vocação contribui de certa forma para responder a uma espécie de fortalecimento da própria docência. A vocação também não é escolhida, porém não seria correto dizer que me encontro com ela; antes ela me encontra, me chama, e correlativamente a descubro; não me é imposta, e sim apresentada, e embora não esteja em minhas mãos ter ou não ter essa vocação, permaneço frente a ela com uma essencial liberdade: posso segui-la ou não, ser fiel ou infiel a ela (MARÍAS, 1983, p.24).

Todavia, colocar a escolha de um ciclo de vida, por vezes de mais de trinta anos, em um elemento subjetivo como a vocação segue um roteiro clássico, quase jesuítico, de escolha sem considerar as consequências.

Nóvoa (1999) afirma que a origem da discussão sobre a profissionalização docente está presente a partir do século XVIII, quando decisões tomadas instigam a imagem social do professor até o Século XX. Discutia-se, por exemplo se o professor deveria ser leigo ou religioso, escolhido ou nomeado. Ainda, segundo Nóvoa (1999), não houve, a partir de então, mudanças significativas nos valores originais da profissão ou em suas normas de conduta e, assim, a docência moderna foi construída em parâmetros vicinais ao sacerdócio que por sua vez estão muito próximo a "vocação".

Um educador, quando consegue, com uma conversa ao pé do ouvido, transformar rebeldia em desafio, quando, através das letras consegue transformar vergonha em orgulho, impossibilidade em desafio, anomia em História, é efetivamente um deus, e pobre dele se não se sentir como tal.
(...) É um deus com pés de barro (CODO, 1999, p. 368).

Responder que a vocação é elemento basilar de escolha parece ser uma resposta simplista diante da complexidade imbricada nas práticas cotidianas da profissão docente. Refletir sobre o que significa, de fato, essa escolha e suas consequências requer a necessidade de aprofundamento conceitual constante.

O professor acredita poder melhorar a realidade através do trabalho. Ele acredita nisso e investe na construção de um ideal. Ele trabalha arduamente além das horas remuneradas, conversa com pais e com profissionais para "salvar" alunos, enfim, toma voluntariamente uma série de medidas em busca de garantir a realização do seu "ato divino". Em função desse ideal, sempre se conseguem novos candidatos à docência, e os antigos, por mais cansados que estejam, continuam fiéis ao exercício de sua profissão. (LENGERT, 2011, p.8, grifos no original).

Porém, se for considerado que a escolha pela docência pode acontecer em qualquer momento da vida e não apenas nos anos finais do ensino médio ou durante os cursos de graduação não há momentos de ponderação sobre vantagens e desvantagens da escolha.

Arroyo (2000) acredita que a ideia de vocação para o magistério não seria tão somente um resquício de uma visão religiosa que ainda perdura no imaginário social e na autoimagem. Antes, segundo o autor, essa ideia poderia estar presente no próprio conceito de profissão, de professor, de profecia.

A "vocação" depende da construção de um imaginário pessoal e não pode ser considerada apenas elemento subjetivo sobretudo em relação às escolhas em relação à profissão docente. Provavelmente ao afirmar que escolheu a carreira considerando inicialmente a vocação o professor ficou perdido no conflito entre a desvalorização salarial e a responsabilidade social considerando que mesmo sem remuneração que realmente pague pelos serviços o docente continua nas salas de aulas exercendo seu ofício assemelhando-se novamente ao 
sacerdócio cuja discussão começou no século XVIII. A propensão pela docência é sistemática e não pode ser descrita somente pelo prisma vocacional individual numa progressão incomplexa.

Mesmo na sociedade da informação e do conhecimento é comum que os professores falem de aspectos como paixão, amor e vocação para justificar suas atividades laborativas na docência. Não se pode julgar como sendo um posicionamento negativo quando o docente agrega esses sentimentos nas justificativas. Pelo contrário, ao lidar com pessoas em formação esses aspectos geram relações de respeito e ajudam ao indivíduo aprendiz a solidificar aprendizagens que vão além dos conteúdos programáticos.

Esse aspecto poderia adentrar o campo negativo se o docente que se diz vocacionado não tivesse nenhum compromisso com a formação contínua ou fosse totalmente relapso com seu compromisso diante das instituições escolas e consequentemente seus alunos.

Nas falas dos docentes entrevistados e nas diversas fontes que discutem o tema é comum encontrar professores que afirmam amar a profissão, mas que buscaram ir ao limite da formação se qualificando constantemente, experimentando e inovando.

\section{A vocação e a tradição familiar}

Os estudos sobre tradição familiar, normalmente, voltam-se para grupos privilegiados da sociedade e descrevem histórias de sucesso de famílias que acumularam riquezas ou determinam destinos. É razoavelmente comum encontrar estudos dessa natureza relacionados à participação política de determinada família, ou mesmo sobre a importância econômica do grupo familiar num contexto histórico. No entanto, é incomum estudos a respeito de um grupo familiar que optou pela educação. Trabalhos sobre grupos menos privilegiados apenas recentemente têm sido elaborados.

Assim a história da profissão docente é indissociável do lugar que seus membros ocupam relações de produção e do papel que desempenha na manutenção da ordem social. Os professores não vão somente responder a uma necessidade social de educação, mas também criá-la. A grande operação histórica da escolarização jamais teria sido possível sem a conjugação de vários fatores de ordem econômica e social, mas é preciso não esquecer que os agentes desse empreendimento foram os professores. NÓVOA, 1988, p. 75 76)

Tradicionalmente famílias influentes tinham entre os seus membros profissionais prestigiosos no contexto social em que estavam inseridos. A partir do início do Século XX, tem início a "feminilização" do magistério pautado na valorização da moral tornando o ensino, ministrado pelas mulheres, não como instrução, mas como disciplinador de condutas.

[...] a ênfase do ensino feminino [era] nas boas maneiras, nas técnicas, na aceitação da vigilância, na aparência, na formação moralista. Coisa adequada quando o ensino fundamental se destinava às classes populares, pois o que estava em jogo não era difundir as perigosas luzes do saber, mas disciplinar as condutas e refrear a curiosidade (CATANI, 1997, p.28)

Nesse sentido, a "vocação" começa a fazer parte do contexto de atuação docente considerando que houve, pela sociedade, uma espécie de conexão da atividade de magistério a um "dom" feminino embasados no fato de que a mulher gera filhos e cuida de crianças tornando a tarefa de educar/escolarizar uma função feminina. Nesse contexto, a mulher deveria seguir sua "vocação". Para Schaffrath (2000, p. 15) “[...] trabalhar como professora e se sujeitar a uma baixa remuneração fazia parte do perfil vocacional das mulheres."

Esse é um elemento que contribui para a desvalorização do profissional da educação e que não aconteceu por acaso no Brasil.

Os professores nunca viram seu conhecimento específico devidamente reconhecido. Mesmo quando se insiste na importância da sua missão, a tendência é sempre para considerar que lhes basta dominarem bem a 
matéria que ensinam e possuírem um certo jeito para se comunicar e lidar com os alunos. O resto é dispensável. Tais posições conduzem a, inevitavelmente ao desprestigio da profissão, cujo saber não tem qualquer valor de troca de mercado (NÓVOA, 2006, p.33).

Ao longo do Século XX essas situações foram sendo calcificadas ao ponto de tornar-se lugar comum $\mathrm{o}$ fato de mulheres serem professores, principalmente nos primeiros anos do ensino fundamental confundindo-se como uma cuidadora de criança e sendo tratada de "tia".

As escolas povoaram-se de mulheres "vocacionadas para o magistério" com formação acadêmica mínima contribuindo para a construção de um caminho linear composto pela docência e a vida cotidiana do casamento. Segundo Freitas (2000) a mulher não precisava ter boa formação, bastava-lhe aprender as primeiras letras e os cálculos aritméticos básicos para assegurar as tarefas do lar.

A vocação acabou ligada às questões de afetividade, cuidado, responsabilidade sobre crianças sem a clara necessidade de aprimoramento de conhecimentos, métodos e técnicas de inovação do ensino. Uma boa professora seria, tradicionalmente, a vocacionada.

Todavia, outros fatores se relacionam de forma próxima e abrem espaços não apenas paras as "vocacionadas", mas também para os "vocacionados" como empregabilidade, rentabilidade fixa, falta de opção no contexto social em que está inserido, a mais fácil escolha, sentimento fantasioso de transformação da sociedade através da autoridade de conhecimento em sala de aula. Segundo Almeida (1998, p. 82) os “[...] homens também são professores e cuidam da família, porem raramente são descritos nesses afazeres, como se tal fato devesse permanecer oculto."

Nesse contexto, os homens marcam a sua atuação, porém sob outro prisma. Para Fernandes (2004) a escolha profissional não uma decisão exclusivamente individual, mas vinculada a diversos fatores; por isso, os professores podem ressaltar o gosto pela profissão como principal motivador para a opção pelo magistério, mas não deixam de destacar outros aspectos como influência da família, questões econômicas, gosto por crianças e um desejo de transformar. Na visão de Pardal e Martins (2006), as escolhas profissionais dos alunos são marcadas pelas representações mais típicas do seu grupo, por isso as pessoas próximas interferem e influenciam nas opções de cada um.

Alves (1997, p. 89), destaca que "[...] a razão das aspirações pessoais de ingressar na profissão docente está ligada tradicionalmente pelas teorias inatistas ou do dom, ao problema da motivação interior - vocação para a docência". Escolhem a profissão docente considerarem que tem vocação para as salas de aula.

\section{Conclusões}

A opção vocação não tinha sido considerada quando o estudo começou. Todo o esforço foi empreendido em aspectos mais palpáveis para interpretar as muitas facetas da carreira docente. Acreditava-se que elementos ligados à formação poderiam ser citados de forma bem clara, porém ficou notório nas falas (entrevistas) que a profissão docente tem uma áurea romântica, que remete os professores a uma espécie de sentimento de salvação ou redenção dos que estão sob sua responsabilidade.

A paixão pelo exercício do magistério não é tão fácil de desenhar ou delimitar com opções definidas dentro de um questionário de perguntas fechadas. Tudo vai além do exposto e sempre há um algo mais a desvendar.

Determinar um ciclo de vida, início da carreira até a aposentadoria, partindo de um elemento subjetivo, como a vocação, não é realmente fácil de explicar e deixa uma brecha para que se possa pensar até que ponto outros aspectos da existência são determinados por sentimentos subjetivos ou crenças preconcebidas.

Pensar que a escolha pela carreira docente é simplista do ponto de vista de ligar dois pontos, magistério e pessoas, é desconsiderar todo um processo que passa o 
candidato a professor que extrapola o limiar da vocação. Não foram apenas aspectos de cunho moral e ético que promoveram a influência para o sujeito seguir pelas salas de aulas considerando que não se pode esquecer que qualquer atividade laborativa implica em remuneração o sujeito que se propõe a executála. Portanto há mais aspectos imbricados em todo esse emaranhado de fatos e sentimentos.

Ao ouvir professores que também são técnicos ou exercem outras atividades além da docência torna a questão um pouco mais complexa e necessária de aprofundamento sobre o autoconhecimento do professor que ama sua profissão e faz dela sua vida dentro e fora das salas de aula. Afinal, a carreira docente é uma decisão para toda a vida.

Que outros profissionais escolhem suas carreiras através desse parâmetro?

\section{AGRADECIMENTOS}

Agradecemos aos professores convidados que contribuíram com suas histórias de vida na composição desse trabalho.

\section{REFERÊNCIAS}

ALMEIDA, J. S. Mulher e educação: a paixão pelo possível. São Paulo: UNESP, 1998.

\section{ALVES, F. C. O encontro com a realidade docente: estudo exploratório (Auto) biográfico. 1997. 711 f. Tese (Doutorado em Ciências da Educação) - Programa de Pós- graduação em Ciências da Educação, Faculdade de Psicologia e de Ciências da Educação, Universidade de Lisboa, Lisboa, 1997.}

ANDRÉ, M.E. D. de. Perspectivas atuais da pesquisa sobre docência. In : BUENO, B.; CATANI, D. B.; SOUSA, C. P. de et al . Docência, memória e gênero: estudos sobre formação. São Paulo: Escrituras, 1997. p. 6574.

ARROYO, M. G. Ofício de mestre: imagens e autoimagens. Petrópolis: Vozes, 2000
CATANI, D. et al. História, memória e autobiografia da pesquisa educacional e na formação. In: CATANI, D. et al. (org.) Docência, memória e gênero: estudos sobre formação. São Paulo: Escrituras Editora, 1997.

CODO, W. (Coord.). Educação: carinho e trabalho: Burnout, a síndrome da desistência do educador, que pode levar à falência da educação. Petrópolis: Vozes, 1999.

DUBAR, C. A socialização: construção das identidades sociais e profissionais. Porto: Porto Editora, 1997.

ENCORE, D. (Org.) Ser professor. 4. ed. Porto Alegre: EDIPUCRS, 2004

FERNANDES, M. C. S. G. Escolha profissional e pratica docente: o discurso de professores do ensino superior privado. In: REUNIAO ANUAL DA ANPED, 27., 2004, Caxambu. Anais... Caxambu: Associação Nacional de Pós-graduação e Pesquisa em Educação, 2004.

FREIRE, P. Pedagogia da Autonomia: saberes necessários à prática educativa. 21.ed. Rio de Janeiro: Paz e Terra, 2002

FREITAS, M. T. de A. (org.) Memória de professoras: história e histórias. Juiz de Fora: UFJF, 2000.

GATTI, B. Os professores e suas identidades: o desvelamento da heterogeneidade. Cadernos de Pesquisa. São Paulo, n.98 p.85-90, ago, 1996.

GHEDIN, E.; FRANCO, M.A.S. Questões de método: na construção da pesquisa em educação. São Paulo: Cortez, 2008.

GIL, A. C. Métodos e técnicas de pesquisa sócia. 6.ed. São Paulo: Atlas, 2008

HELLER, A. O cotidiano e a história. 4. Ed. Rio de Janeiro: Paz e Terra, 1992.

HOLLY, M. L. Investigando a vida profissional dos professores: diários biográficos. IN; NÓVOA, Antonio (Org.) 
Vida de professores. Porto: Porto, 1992.

Os professores e suas histórias de vida. IN; NÓVOA, Antonio (Org.) Vida de professores. Porto: Porto, 1992.

HUBERMAN, M. O ciclo de vida profissional dos professores IN; NÓVOA, Antonio (Org.) Vida de professores. Porto: Porto, 1992.

JOWETT, J. H. O pregador, sua vida e obra. São Paulo: CEP, 1969.

LAUDARES， J.B; FIUZA,J.R.;ROCHA,S. Educação tecnológica: os impactos nos projetos pedagógicos dos cursos técnicos dos CEFETS Minas Gerais e Paraná pelos Decretos 20.208/97 e 5.1547/04. In: ARANHA, A. V.; CUNHA, D.M.; LAUDARES, J.B (Org.). Diálogos sobre trabalho: perspectivas multidisciplinares. Campinas: Papirus, 2005.

LENGERT, R. Profissionalização docente: entre vocação e formação. Educação, Ciência e Cultura. Canoas/RS v. 16, n. 2 (2011). Disponível em http://www.revistas.unilasalle.edu.br/index.p hp/Educacao/issue/view/38 . Acesso em: 26 agosto de 2016

MARÍAS, J. O.: Las trayectorias. Madrid, Alianza Editorial, 1983.

MOREIRA, H.; CALEFFE, L.G. Metodologia da pesquisa: para o professor pesquisador. Rio de Janeiro: Lamparina, 2006.

NÓVOA, A. A formação tem que passar por aqui: as histórias de vida no projecto prosalus. In: NÓVOA, A.; FINGER, M. (Org.). O método (auto)biográfico e a formação . Lisboa: Ministério da Saúde, 1988.

NÓVOA, A. O passado e o presente dos professores. In: NÓVOA, A. (Org.). Profissão Professor. Lisboa: Porto Editora, 1999.

NÒVOA. A. O professor e o novo espaço público de educação. Educação e Sociedade: Perspectivas educacionais no Século XXI. Santa Maria, RS. UNIFRA, 2016.
PARDAL, L.; MARTINS, A. As representações sociais e o sentido das escolhas académicas. Aveiro: Universidade de Aveiro, 2006.

SACRISTAN, G. Consciência e ação sobre a prática como libertação profissional dos professores. In: NÓVOA, A. (Org.) Profisssão Professor. Lisboa: Porto Editora, 1999.

SCHAFFRATH, M.A.S. Profissionalização do magistério feminino: uma história de emancipação e preconceitos. In: REUNIAO ANUAL DA ANPED, 23., 2000, Caxambu. Anais... Caxambu: Associação Nacional de Pós-graduação e Pesquisa em Educação, 2002.

TRIVIÑOS, A. N. S. Introdução à pesquisa em ciências sociais : a pesquisa qualitativa em educação. São Paulo: Atlas, 1987. 